\title{
ARTICLE
}

Received 12 Sep 2013 | Accepted 17 Dec 2013 | Published 15 Jan 2014

DOI: $10.1038 /$ ncomms 4144

\section{Evolution of long-toothed fishes and the changing nature of fish-benthos interactions on coral reefs}

David R. Bellwood ${ }^{1,2}$, Andrew S. Hoey², Orpha Bellwood ${ }^{1}$ \& Christopher H.R. Goatley,2

Interactions between fishes and the benthos have shaped the development of marine ecosystems since at least the early Mesozoic. Here, using the morphology of fish teeth as an indicator of feeding abilities, we quantify changes over the last 240 million years of reef fish evolution. Fossil and extant coral reef fish assemblages reveal exceptional stasis in tooth design over time, with one notable exception, a distinct long-toothed form. Arising only in the last 40 million years, these long-toothed fishes have bypassed the invertebrate link in the food chain, feeding directly on benthic particulate material. With the appearance of elongated teeth, these specialized detritivores have moved from eating invertebrates to eating the food of invertebrates. Over evolutionary time, fishes have slid back down the food chain.

\footnotetext{
${ }^{1}$ School of Marine and Tropical Biology, James Cook University, Townsville, Queensland 4811, Australia. ${ }^{2}$ Australian Research Council Centre of Excellence for Coral Reef Studies, James Cook University, Townsville, Queensland 4811, Australia. Correspondence and requests for materials should be addressed to D.R.B. (email: david.bellwood@jcu.edu.au).
} 
O ne of the central goals in evolutionary ecology is to understand changes in the nature of biotic interactions over time $\mathrm{e}^{1-3}$. As top predators in marine systems for the last 450 million years (My), fishes have played a key role in these interactions $s^{4,5}$. Changes in jaw and tooth structure of vertebrates have been key indicators of changing feeding modes through time ${ }^{6-8}$. However, no comprehensive overview of tooth structure in fish assemblages has been undertaken. Here we show that fish teeth have been remarkably consistent for at least $240 \mathrm{My}$ with a single major innovation, a long-toothed form, which reaches its zenith on Recent coral reefs. This long, flexible tooth supports a new feeding mode, specialized detritivory, which enables fish to feed almost exclusively on particulate material, a diet traditionally associated with invertebrates ${ }^{9}$. This appears to be the final evolutionary step as fishes move down the food chain from carnivory to herbivory and finally, detritivory.

In palaeontology, there is extensive documentation of changes in the taxonomic composition of faunas through time $\mathrm{e}^{10-12}$. Documenting changes in ecological processes (that is, the interactions between the organisms and their environment) is much harder ${ }^{2}$. Yet these are the driving forces behind much of evolution and are critical to our understanding of the communities we see today ${ }^{1-3}$. Changes in biotic interactions over time are inevitable, but the nature and pace of these changes may have a profound influence on the course of evolution ${ }^{13-15}$. Coral reefs, for example, represent one of the most complex and dynamic ecosystems and display a wide variety of interactions between nektonic and benthic organisms. Of these interactions, predation and herbivory stand out as the primary determinants of benthic community structure and the reef community as a whole ${ }^{1,13,15,16}$. The history of these interactions, however, is less clear. Vermeij ${ }^{1}$ first highlighted the potential impact of changing interactions in his description of the Mesozoic Marine Revolution (MMR), which was marked by a gradual increase in predation throughout the Mesozoic (201-65 Million years ago [Ma]). While the pattern and implications of the MMR has been questioned $^{11}$, an increase in predation remains a likely feature of the Mesozoic seas ${ }^{17}$. Subsequent studies have documented the rise of herbivory and associated changes in benthic community structure over the last $200 \mathrm{My}$, particularly a decline in grazingsusceptible algal taxa ${ }^{13,14}$. These changes in the benthos mirror shifts in grazing invertebrate groups in the Mesozoic and the rise of grazing fishes in the Cenozoic ${ }^{13,14}$. These latter changes in fishes represent part of a broader reassembly of fish morphotypes through time $\mathrm{e}^{18,19}$.

In many cases, changes in fish morphology and the appearance of new higher taxonomic groups mark major shifts in the nature of fish-benthos interactions ${ }^{14,19,20}$. However, on modern reefs, and in aquatic systems in general, herbivory and other biotic interactions are characterized by considerable complexity ${ }^{16,21}$. Fishes vary greatly in how they feed. In many systems today, in terms of ecosystem processes, it is the type of herbivore and subtle differences in feeding morphology that shape benthic community structure $^{15,16,21,22}$.

Distinguishing various herbivore types is not easy. However, several independent studies have highlighted the importance of tooth morphology in shaping feeding modes ${ }^{22-25}$. In terms of food procurement, the teeth are literally on the cutting edge. Our goal, therefore, was to re-evaluate the morphology of fish teeth since the Triassic, particularly in those taxa living in the vicinity of coral reefs. We show that the morphology of fish teeth has changed little over the past 240 My with one notable exception that appears to have changed the nature of fish-benthos interactions. The appearance of long-toothed fishes in the last $40 \mathrm{My}$ is associated with feeding on particulate material. These specialist detritivores mark an expansion in the range of trophic categories consumed by fishes and represent an incursion into a trophic mode that was traditionally the domain of invertebrates.

\section{Results}

Tooth morphology over time. A principal component analysis (Fig. 1, Supplementary Fig. 1) revealed that the volume of the Recent tooth morphospace occupied by fishes exceeded that of all previous periods (randomized permutation test, $P<0.041$, Supplementary Fig. 2, Supplementary Table 1). However, the occupation of this morphospace was uneven. A cluster analysis, and subsequent ANOSIM, revealed three groups centred at each vertex of the Recent morphospace (Global $\mathrm{R}=0.99, P=0.001$; Supplementary Fig. 1). Two of these groups, separated along PC1, have been occupied throughout the time period examined in our study.

The persistence of ancient tooth morphologies. PC1 revealed a major axis of diversification in fishes with the extremes marked by forms with widely spaced, pointed caniniform teeth to forms
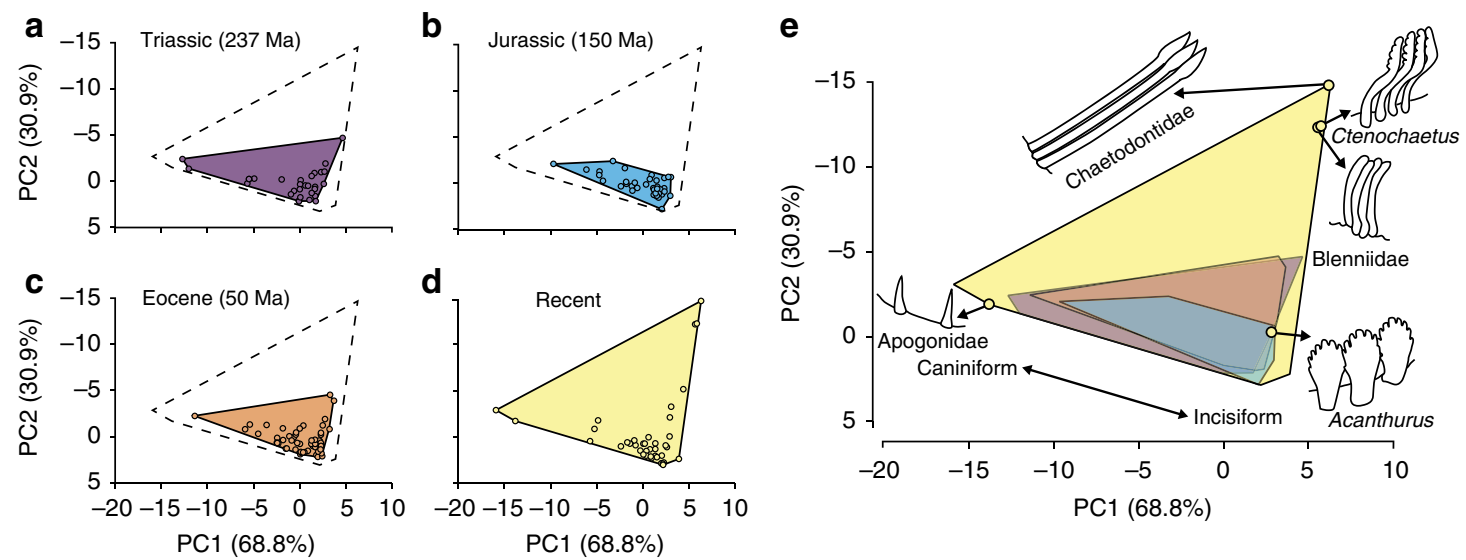

Figure 1 | A comparison of reef fish tooth morphologies over the last $\mathbf{2 4 0}$ million years reveals the rise of new long-toothed fishes. (a) Species from Triassic (237-204 Ma); (b) Jurassic (151-146 Ma); (c) Eocene (50 Ma) and (d) Recent assemblages. (e) All data combined with examples of teeth from five extant species. The PCA was conducted on body-length standardized residuals of five relative shape variables. Dashed lines indicate the maximum area of tooth morphospace occupied by Recent fishes. 
with closely spaced incisiform teeth. This axis is strongly represented in all four faunas spanning the entire $240 \mathrm{My}$. Functionally, this equates to an axis ranging from piercing graspers that feed on whole, large prey items, to chopping or scraping forms that feed on smaller prey items or remove pieces of larger prey. Relatively fine dagger-like caniniform teeth in the piercing graspers are well suited for puncturing flesh ${ }^{24}$. While protective measures of prey may have changed over time, with fish trading off armour plating for manoeuvrability ${ }^{26}$, the underlying material, and the teeth needed to penetrate it, appears to have remained remarkably consistent. Similarly, the removal of pieces of larger prey, be it part of a crab, alga or echinoid, appears to have presented a relatively consistent challenge with minimal changes to incisiform morphologies. Remarkably, the functional and morphological structure of the fish assemblages has remained the same despite a complete taxonomic turnover of all higherlevel taxa over the study period ${ }^{25}$.

The rise of long-toothed fishes on Recent coral reefs. Perpendicular to this traditional axis of variation is a major excursion into novel morphospace; one characterized by the possession of extremely long teeth, particularly in terms of their length relative to the size of the jaw (Figs 1 and 2). This morphospace is occupied by three Recent fish groups (the combtooth blennies, bristletooth surgeonfishes and butterflyfishes), represented by approximately 450 species on modern coral reefs. To our knowledge, such teeth have not been recorded from any other marine fish group, fossil or extant. These new long-toothed forms are closely linked with a feeding mode focusing on small and relatively soft food items. In particular, this novel tooth morphospace is closely associated with a highly modified kind of herbivory: the specialized detritivore.

\section{Discussion}

Fishes have ingested particulate material since at least the Devonian, with agnathans and some placoderms probably engulfing and bulk-processing benthic sediments and the associated fauna from a muddy seabed ${ }^{27-29}$. Similarly, on modern coral reefs, many groups include some detritus in their $\operatorname{diet}^{9}$. These facultative detritivores include groups that are also recorded from the Eocene, for example, the damselfishes, gobies and rabbitfishes ${ }^{24}$. However, it is important to separate facultative detritivory from specialized detritivory. In the former, detritus is included as one of a number of dietary items and is not associated with behavioural or morphological modifications. Indeed, detritus is ubiquitous in aquatic systems and some ingestion is almost inevitable. Approximately a quarter of extant reef fishes include some detritus in their diet ${ }^{9,30}$ and similar consumption of detritus is likely to have occurred in the past, as morphologically 'cryptic' facultative detritivory.

In contrast to facultative detritivory, specialized reef-based detritivory is much more restricted. In specialist detritivores, the bulk of the diet, both energetically and nutritionally, is based on particulate material ${ }^{9}$. This unusual feeding mode is also associated with distinct morphological changes or innovations. Rows of extremely long, tightly packed teeth are a widespread characteristic of selective substratum-feeding (that is, specialized) detritivores. In marine systems, such long-tooth based detritivory has arisen at least twice, in the combtooth blennies and the surgeonfishes (represented here by Salarias and Ctenochaetus). In both groups, the key to their feeding mode is the structure of the teeth. This represents an independently derived morphologicalfunctional innovation, where long flexible teeth enable these taxa to selectively remove fine detrital particles from algal turfs $9,23,31$. The strong similarity in tooth morphology among groups, and
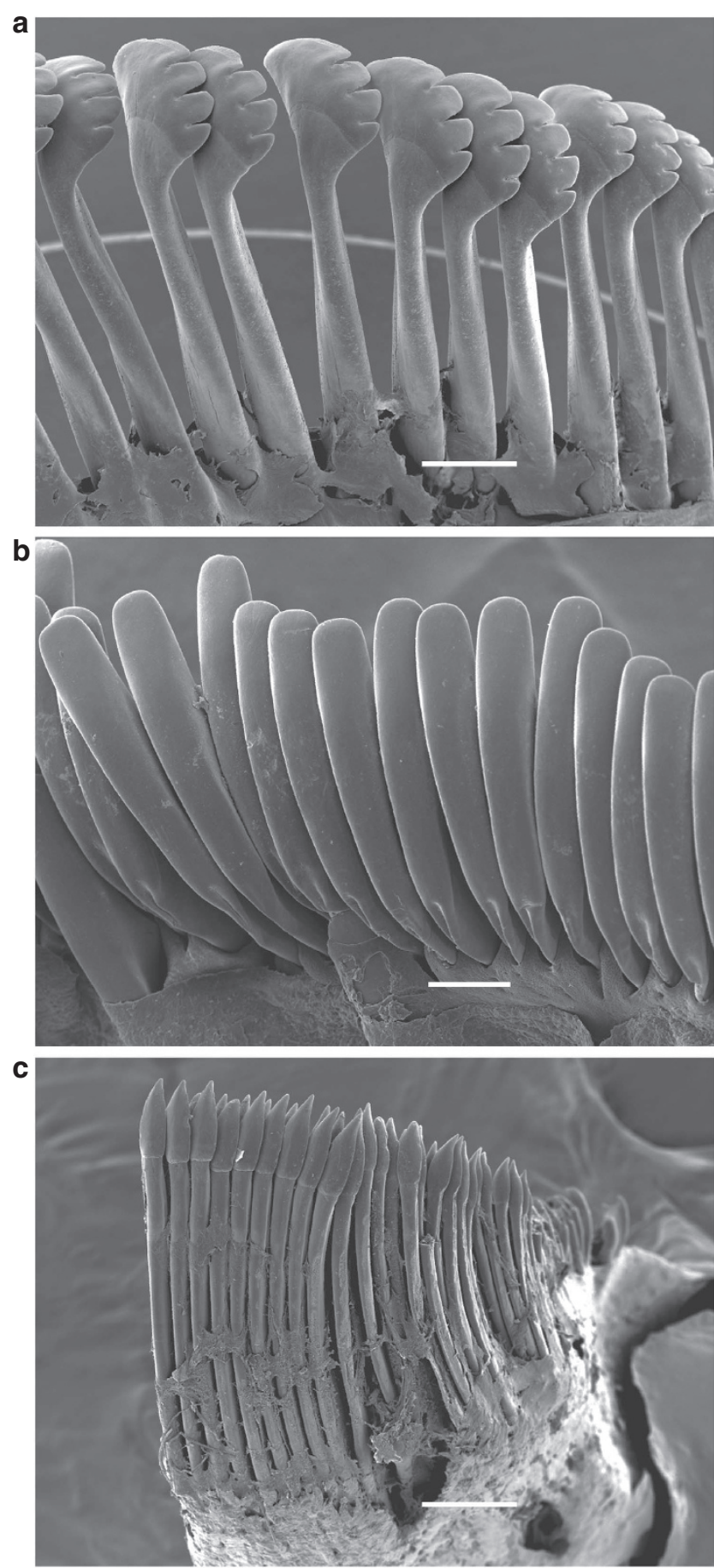

Figure 2 | Long teeth from Recent coral reef fishes. SEM images of the teeth of (a) Ctenochaetus striatus (Acanthuridae), (b) Salarias fasciatus (Blenniidae) and (c) Chaetodon vagabundus (Chaetodontidae); representatives of the three taxa of reef fishes displaying the Recent long-toothed morphology. Scale bars represent $500 \mu \mathrm{m}, 100 \mu \mathrm{m}$ and $500 \mu \mathrm{m}$, respectively.

the associated trophic shifts, suggests that this is an example of convergent evolution driven by functional adaptations. This suggestion is supported by parallel changes in freshwater systems.

Several freshwater groups also exploit this feeding mode, including cichlids, plecoglossids (ayu) and loricariid (armoured) catfishes. Occurring in highly productive, shallow freshwater ecosystems, these groups also have detritivorous taxa with 
flexible, elongate, closely spaced teeth ${ }^{32-36}$, similar to those seen in specialized detritivores on coral reefs. The similarity in morphology between marine and freshwater groups reflects a common challenge, selectively removing fine particulate material from algal turfs on a hard substratum (the epilithic algal matrix, EAM on reefs ${ }^{37}$ and aufwuchs in the African rift lakes ${ }^{33}$ ).

There are no comparable tooth structures in the Eocene fauna examined. In the two key coral reef taxa (Ctenochaetus and combtooth blennies), molecular evidence indicates that these two lineages arose relatively recently (both within the last $25 \mathrm{My}^{38,39}$ ), suggesting that such specialized detritivory is a relatively new trait in reef fishes (the only other major detritivorous group on reefs, parrotfishes, likewise diverged relatively recently at about 16 $\mathrm{Ma}^{40-42}$, again with highly modified dentition). The third longtoothed group, the butterflyfish (Chaetodontidae), use their elongate, hooked teeth in batteries to form a 'Velcro-like' $\mathrm{pad}^{43}$, which allows them to feed on a wide array of small soft benthic items, from coral polyps and mucous to polychaetes (molecular evidence indicates that this group likewise diverged relatively recently with origins of the family about $32 \mathrm{Ma}^{44,45}$ ).

On coral reefs, the observed changes in tooth morphology reflect previous accounts of expanding herbivory in the Eocene $\mathrm{e}^{13,14}$, with the possibility of facultative detritivory in early members of the Pomacentridae, Siganidae and Acanthuridae, followed by multiple lineages displaying specialized detritivory in the Miocene ${ }^{41}$. It is interesting that specialized detritivory arose so late in reef fish history, as most reef fish families, and associated feeding modes, were well established in the early Cenozoic ${ }^{19,41,46}$. The Cenozoic thus seems to have had two waves of trophic innovation, with an early Palaeocene-Eocene phase in which major reef fish groups and basic feeding modes were established, and a later OligoceneMiocene phase where more specialized feeding modes arose.

These phases coincide with a major realignment in the history of coral reefs, marked by an Eocene-Oligocene mass extinction event $^{45}$, an expansion of coral reefs in the Indo-Australian Archipelago (IAA) ${ }^{47}$ and a shift in tropical global biodiversity from the west Tethys to the IAA ${ }^{48}$. The rapid expansion of reefal taxa in the IAA $^{45,49}$ included fishes that exploit detritus-bearing algal turfs and fast-growing corals ${ }^{4,45}$. The latter following geographic expansion of fast-growing branching corals, especially Acropora species. This suggests that early Cenozoic reefs were energetically and trophically different from their Miocene counterparts. The latter having a modern configuration characterized by a large number of fish groups that are tied to fast-growing high-productivity components of the benthos such as Acropora and the short algal turfs that contain most reef-based detritus $^{9,45}$.

Today, specialized detritivores constitute a major component of coral reef fish communities, and detritus is the basis of a key pathway for primary production to pass up the food chain via fishes ${ }^{9,30}$. Considering facultative and specialized detritivores together, on many coral reefs, detritivores outnumber algal-eating herbivores in terms of both the number of species and their densities ${ }^{9,30}$.

Fishes feeding on hard substrata have thus progressively moved down the food chain from predators and choppers in the Devonian $(380 \mathrm{Ma})^{5,50,51}$, to include herbivory and facultative detritivory in the early Paleogene $(60-50 \mathrm{Ma})^{13,14}$, and finally specialized detritivory in the Neogene ( $35 \mathrm{Ma})$. These specialized detritivores are now exploiting a diet that was the traditional domain of invertebrates. In the past, invertebrates ate particulate material and fish ate the invertebrates. This still happens. However, on modern reefs, some fishes have moved down the food chain and directly exploit algae, microbial material and detritus. With each step, the intensity and pace of fish-benthos interactions increased, as fishes consumed more types of food and increasingly smaller prey; the zenith being specialized detritivorous fishes, which consume predominantly particulate organic matter and microbes. These items are characterized by high rates of consumption, rapid digestion and the potential to support a dynamic high-productivity low standing-stock system ${ }^{9}$, the essence of a modern coral reef ecosystem.

\section{Methods}

Material examined. Fossil fishes (121 species; Supplementary Table 2) were examined from five exceptionally rich fossil deposits (Lagerstätten): Monte San Giorgio, Switzerland (Middle Triassic; Anisian-Ladinian; approximately $237 \mathrm{Ma}$ ) and Zorzino, Italy (Upper Triassic; Norian; 216.5-203.6 Ma), combined to provide a single Triassic sample; Solnhofen, Germany (Upper Jurassic; Tithonian; 150.8145.5 Ma); and Monte Bolca, Italy (Eocene; Ypresian-Lutetian; ca. $50 \mathrm{Ma})^{19}$. These were compared with representatives from 45 extant genera from the Great Barrier Reef (GBR). The fossil assemblages all had coral-bearing hard grounds in the vicinity and, with excellent preservation, provide an indication of the functional capabilities of fishes in the vicinity of coral reefs through time ${ }^{14,19,25}$.

Morphological analyses. To avoid subjective classifications of tooth morphology, quantitative measurements of teeth were taken directly from camera lucida drawings of the largest lateral tooth in the anterior part of the jaw. Seven measurements were taken from each tooth and converted into five shape variables (Fig. 3, Supplementary Data 1).

Relative tooth length. Shape variable 1: relative tooth length was calculated as tooth height divided by base width ( = A/B; Fig. 3), with values of $<1$ representing teeth wider than tall and $>1$ representing teeth taller than wide (Supplementary Fig. 3A).

Gap width. Shape variable 2: gap width was calculated as the distance between teeth $10 \%$ below the tip divided by the width of the tooth at the same level $(=\mathrm{D} / \mathrm{C}$; Fig. 3). This is essentially a measurement of tip spacing, with a score of 1 representing fish with the tips of their teeth being as far apart as they are wide. Greater than 1 indicates more widely spaced tips and less than 1 more closely packed (Supplementary Fig. 3B).

Height ratio. Shape variable 3: height ratio is a measure of tooth tip roundness (lateral curvature). It is derived from measurements of tooth height above the widest part of the tooth. If a tooth is widest at the base, this measure gives an indication of overall tooth pointedness (Supplementary Fig. 3C). But not all teeth are widest at the base (see area below triangles delineated by a grey dashed line, Supplementary Fig. 3C), and, as such, this measure is better thought of as an index of tip pointedness. The ratio is calculated using the equation: height ratio $=F / G$ (Fig. 3). Height ratios below 0.5 have convex sided tips (that is, bluntly rounded) and those above 0.5 have concave sided tips (that is, relatively sharp or pointed) A value of exactly 0.5 shows a tooth with straight sides. Some teeth do not reach $50 \%$ of their maximum width (E/2; Fig. 3 ) and as such have no height above this value (F; Fig. 3); their height ratio is therefore 0 (see example in the left panel of Supplementary Fig. 3C).

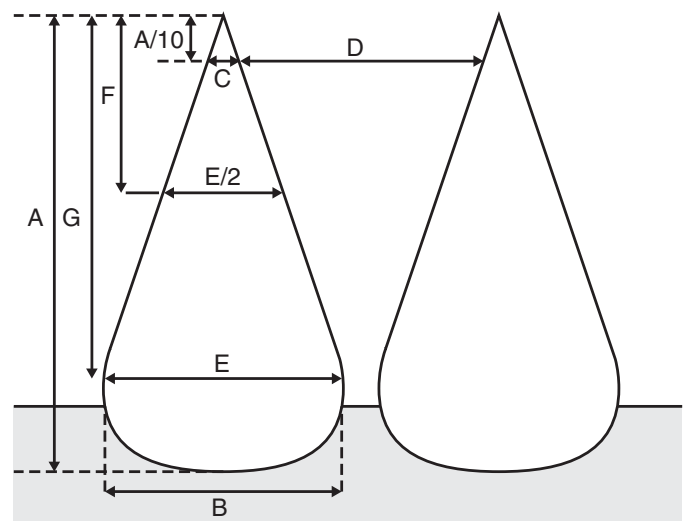

Figure 3 | Measurements taken from fossil and extant fish teeth. (A) Tooth height, (B) tooth basal width, (C) tooth width $10 \%$ down from tip, (D) gap between teeth $10 \%$ down from tip, (E) maximum tooth width, (F) height of tooth above $50 \%$ maximum tooth width, (G) height of tooth above maximum tooth width. 
Tooth size. Shape variable 4: tooth size is a ratio of tooth height relative to jaw length, measured from the lower jaw articulation to the tip of the distal tooth ( = G/jaw length; Fig. 3 and Supplementary Fig. 3D). This is a measure of tooth size (specifically height), relative to the jaw. The largest tooth size recorded was 0.5 and the smallest, 0 in edentulate species. Only the largest lateral tooth in the anterior part of the jaw was measured.

Tooth width ratio. Shape variable 5: width ratio is a measure of overall tooth pointedness. The ratio is calculated as the tooth width $10 \%$ below the tip $\div$ maximum tooth width (=C/E; Fig. 3). A cuboid (incisiform tooth) has a width ratio of 1 with values progressing down through convex sided shapes to triangles, which have width ratios of 0.1 . Below 0.1 teeth are pointed, with convex sides (Supplementary Fig. 3E)

Statistical analyses. The morphological composition of each of the four faunas was explored using a principal component analysis of the body-length standardized residuals of the five shape variables. To statistically compare area estimates among periods, we performed randomized permutation testing ${ }^{52} . P$-values were obtained by comparing the distributions of 999 permutations of 25 randomly sampled species from each period. All analyses were undertaken in the program R. Cluster analysis and subsequent analysis of similarities (ANOSIM) were calculated in PRIMER v6 and were used to reveal patterns in the morphological data.

\section{References}

1. Vermeij, G. J. The Mesozoic marine revolution: evidence from snails, predators and grazers. Paleobiology 3, 245-258 (1977).

2. Jablonski, D. \& Sepkoski, Jr J. J. Paleobiology, community ecology, and scales of ecological pattern. Ecology 77, 1367-1378 (1996).

3. Kiessling, W. Life's complexity cast in stone. Science 314, 1254-1255 (2006).

4. Wood, R. Ed. Reef Evolution (Oxford Univ. Press, 1999).

5. Rücklin, M. et al. Development of teeth and jaws in the earliest jawed vertebrates. Nature 491, 748-751 (2012).

6. Van Valkenburgh, B., Wang, X. \& Damuth, J. Cope's rule, hypercarnivory, and extinction in North American canids. Science 306, 101-104 (2004).

7. Anderson, P. S. L. Shape variation between arthrodire morphotypes indicates possible feeding niches. J. Vertebr. Paleontol. 28, 961-969 (2008).

8. Anderson, P. S. L., Friedman, M., Brazeau, M. D. \& Rayfield, E. J. Initial radiation of jaws demonstrated stability despite faunal and environmental change. Nature 476, 206-209 (2011).

9. Wilson, S. K., Bellwood, D. R., Choat, J. H. \& Furnas, M. J. Detritus in the epilithic algal matrix and its use by coral reef fishes. Oceanogr. Mar. Biol. 41, 279-309 (2003).

10. Patterson, C In The Fossil Record 2 (ed. Benton, M. J.) 621-656 (Chapman and Hall, 1994).

11. Alroy, J. et al. Phanerozoic trends in the global diversity of marine invertebrates. Science 321, 97-100 (2008).

12. Raup, D. M. \& Sepkoski, Jr J. J. Mass extinctions in the marine fossil record. Science 215, 1501-1503 (1982).

13. Steneck, R. S. Escalating herbivory and resulting adaptive trends in calcareous algal crusts. Paleobiology 9, 44-61 (1983).

14. Bellwood, D. R. Origins and escalation of herbivory in fishes: a functional perspective. Paleobiology 29, 71-83 (2003).

15. Hughes, T. P. et al. Phase shifts, herbivory, and the resilience of coral reefs to climate change. Curr. Biol. 17, 360-365 (2007).

16. Burkepile, D. E. \& Hay, M. E. Herbivore species richness and feeding complementarity affect community structure and function on a coral reef. Proc. Natl Acad. Sci. USA 105, 16201-16206 (2008).

17. Finnegan, S., McCain, C. M., Kosnik, M. A. \& Payne, J. L. Escargots through time: an energetic comparison of marine gastropod assemblages before and after the Mesozoic marine revolution. Paleobiology 37, 252-269 (2011).

18. Sallan, L. C. \& Friedman, M. Heads or tails: staged diversification in vertebrate evolutionary radiations. Proc. R. Soc. B 279, 2025-2032 (2012).

19. Goatley, C. H. R., Bellwood, D. R. \& Bellwood, O. Fishes on coral reefs: changing roles over the past 240 million years. Paleobiology 36, 415-427 (2010).

20. Sallan, L. C., Kammer, T. W., Ausich, W. I. \& Cook, L. A. Persistent predator-prey dynamics revealed by mass extinction. Proc. Natl Acad. Sci. USA 108, 8335-8338 (2011).

21. Fryer, G. \& Isles, T. D. The Cichlid Fishes of the Great Lakes of Africa: Their Biology and Evolution (Oliver and Boyd, Edinburgh, 1972).

22. Hoey, A. S. \& Bellwood, D. R. Cross-shelf variation in the role of parrotfishes on the Great Barrier Reef. Coral Reefs 27, 37-47 (2008).

23. Purcell, S. W. \& Bellwood, D. R. A functional analysis of food procurement in two surgeonfish species, Acanthurus nigrofuscus and Ctenochaetus striatus (Acanthuridae). Environ. Biol. Fish. 37, 139-159 (1993).

24. Bellwood, D. R. \& Wainwright, P. C. In Coral Reef Fishes: Dynamics and Diversity in a Complex Ecosystem (Ed. Sale, P. F.) 5-32 (Academic Press, San Diego, 2002).
25. Bellwood, D. R. \& Hoey, A. S. In Mesozoic Fishes, Vol. 3. Systematics, Paleoenvironments and Biodiversity. (Eds Arratia, G. \& Tintori, A.) 639-649 (Verlag Dr. Friedrich Pfiel, Munich, 2004).

26. Webb, P. W. \& Smith, G. R. Function of the caudal fin in early fishes. Copeia 1980, 559-562 (1980).

27. Mallatt, J. Feeding ecology of the earliest vertebrates. Zool. J. Linn. Soc. 82, 261-272 (1984)

28. Goujet, D. F. In Encyclopedia of Life Sciences (John Wiley \& Sons, Hoboken, 2002).

29. Goujet, D. F. 'Lungs' in placoderms, a persistent paleobiological myth related to environmental preconceived interpretations. C. R. Palevol. 10, 323-329 (2011).

30. Depczynski, M. \& Bellwood, D. R. The role of cryptobenthic reef fishes in coral reef trophodynamics. Mar. Ecol. Prog. Ser. 256, 183-191 (2003).

31. Wilson, S. K. Trophic status and feeding selectivity of blennies (Blenniidae, Salariini). Mar. Biol. 136, 431-437 (2000).

32. Howes, G. J. \& Sanford, C. P. J. Oral ontogeny of the ayu, Plecoglossus altivelis and comparisons with the jaws of other salmoniform fishes. Zool. J. Linn. Soc 89, 133-169 (1987)

33. Sturmbauer, C., Mark, W. \& Dallinger, R. Ecophysiology of aufwuchs-eating cichlids in Lake Tanganyika: niche separation by trophic specialization. Environ. Biol. Fish. 35, 283-290 (1992).

34. Genner, M. J., Turner, G. F. \& Hawkins, S. J. Foraging of rocky habitat cichlid fishes in Lake Malawi: coexistence through niche partitioning? Oecologia 121, 283-292 (1999)

35. Delariva, R. L. \& Agostinho, A. A. Relationship between morphology and diets of six neotropical loricariids. J. Fish. Biol. 58, 832-847 (2001).

36. Geerinckx, T. et al. Soft dentin results in unique flexible teeth in scraping catfishes. Physiol. Biochem. Zool. 85, 481-490 (2012).

37. Wilson, S. K. \& Bellwood, D. R. Cryptic dietary components of territorial damselfishes (Pomacentridae. Labroidei). Mar. Ecol. Prog. Ser. 153, 299-310 (1997).

38. Near, T. J. et al. Resolution of ray finned fish phylogeny and timing of diversification. Proc. Natl Acad. Sci. USA 109, 13698-13707 (2012).

39. Sorenson, L., Santini, F., Carnevale, G. \& Alfaro, M. E. A multi-locus timetree of surgeonfishes (Acanthuridae, Percomorpha), with revised family taxonomy. Mol. Phylogenet. Evol. 68, 150-160 (2013).

40. Choat, J. H., Klanten, O. S., van Herwerden, L., Robertson, D. R. \& Clements, K. D. Patterns and processes in the evolutionary history of parrotfishes (Family Labridae). Biol. J. Linn. Soc. 107, 529-557 (2012).

41. Cowman, P. F., Bellwood, D. R. \& van Herwerden, L. Dating the evolutionary origins of wrasse lineages (Labridae) and the rise of trophic novelty on coral reefs. Mol. Phylogenet. Evol. 52, 621-631 (2009).

42. Price, S. A. et al. Functional innovations and morphological diversification in parrotfish. Evolution 64, 3057-3068 (2010).

43. Motta, P. J. Dentition patterns among Pacific and Western Atlantic butterflyfishes (Perciformes, Chaetodontidae): relationship to feeding ecology and evolutionary history. Environ. Biol. Fish. 25, 159-170 (1989).

44. Bellwood, D. R. et al. Evolutionary history of the butterflyfishes (f. Chaetodontidae) and the rise of coral feeding fishes. J. Evol. Biol. 23, 335-349 (2010).

45. Cowman, P. F. \& Bellwood, D. R. Coral reefs as drivers of cladogenesis: expanding coral reefs, cryptic extinction events, and the development of biodiversity hotspots. J. Evol. Biol. 24, 2543-2552 (2011).

46. Bellwood, D. R. The Eocene fishes of Monte Bolca: the earliest coral reef fish assemblage. Coral Reefs 15, 11-19 (1996).

47. Wilson, M. E. J. \& Rosen, B. R. In Biogeography and Geological Evolution of SE Asia. (Eds. Hall, R. \& Holloway, J. D.) 165-195 (Backhuys, Leiden, 1998).

48. Renema, W. et al. Hopping hotspots: global shifts in marine biodiversity. Science 321, 654-657 (2008).

49. Cowman, P. F. \& Bellwood, D. R. The historical biogeography of coral reef fishes: global patterns of origination and dispersal. J. Biogeogr. 40, 209-224 (2013).

50. Anderson, P. S. L. Biomechanics, functional patterns, and disparity in Late Devonian arthrodires. Paleobiology 35, 321-342 (2009).

51. Anderson, P. S. L. \& Westneat, M. W. A biomechanical model of feeding kinematics for Dunkleosteus terrelli (Arthrodira, Placodermi). Paleobiology 35, 251-269 (2009).

52. Manly, B. F. J. Ed. Randomization, bootstrap, and Monte-Carlo methods in biology (Chapman and Hall, 1997).

\section{Acknowledgements}

We thank A. Aspes, P. Forey, D. Gouget, H. Lelievre, O. Schultz, L. Sorbini, A. Tintori G. Viohl and R. Zorzin for access to material; K. Blake for SEM images; S. Brandl for analytical assistance. Research was funded by the Australian Research Council (D.R.B.). 


\section{Author contributions}

D.R.B., O.B., A.S.H. collected data, D.R.B. wrote the first draft, A.S.H. and C.H.R.G. analysed the data and all authors edited the manuscript.

\section{Additional information}

Supplementary Information accompanies this paper at http://www.nature.com/ naturecommunications
Competing financial interests: The authors declare no competing financial interests.

Reprints and permission information is available online at http://npg.nature.com/ reprintsandpermissions/

How to cite this article: Bellwood, D.R. et al. Evolution of long-toothed fishes and the changing nature of fish-benthos interactions on coral reefs. Nat. Commun. 5:3144 doi: $10.1038 /$ ncomms4144 (2014). 